\title{
NEGOCIAÇÕES VIA INTERNET: ESTUDO DO COMPORTAMENTO NEGOCIADOR VERSUS CONSUMIDOR ATRAVÉS DA WEB
}

\section{ARTIGO DE REVISÃO}

PORTELLA, Anderson Gonçalves ${ }^{1}$

PORTELLA, Anderson Gonçalves. Negociações via internet: Estudo do comportamento negociador versus consumidor através da web. Revista Científica Multidisciplinar Núcleo do Conhecimento. Ano 06, Ed. 01, Vol. 06, pp. 7495. Janeiro de 2021. ISSN: 2448-0959, Link de acesso: https://www.nucleodoconhecimento.com.br/engenharia-deproducao/negociacoes-via-internet

\section{RESUMO}

Através dos estudos realizados pelo projeto INTERNEG (1996) foram iniciadas pesquisas visando avaliar e levantar hipóteses quanto à influência das novas tecnologias de computação, onde a pequena loja da esquina passou a negociar via web com outro empresário/consumidor que anteriormente não seria cogitado - o negociador virtual. Surgiu então o "negociador sem face", e o "consumidor remoto ou virtual", que geograficamente ou culturalmente estariam interagindo na maximização de suas utilidades. O projeto INTERNEG teve como instrumento de trabalho a ferramenta INSPIRE que permitiria através de um pré-questionário, uma análise das mensagens trocadas entre os negociadores, e de um pós-questionário (não obrigatório), avaliar as negociações feitas entre indivíduos que não se conheciam, assim como o desfecho de suas negociações. O objetivo deste artigo é analisar a

\footnotetext{
${ }^{1}$ Mestre em Economia e Gestão Empresarial, Pós Graduado em Gestão de Projetos, Pós Graduado em Gestão de RH, Pós Graduado em Administração EconômicoFinanceira, Bacharel em Ciências Econômicas, Graduando em Engenharia de Produção.
} 
negociação via internet - precursores do e-commerce, as relações de confiança com o consumidor, os esforços para tornar as negociações mais interativas, e o comportamento do negociador e do consumidor. O método de análise utilizado baseiase na visão estruturalista cujo objetivo é descobrir quais estruturas sustentam todas as coisas que os seres humanos fazem, pensam e percebem, sendo ainda uma corrente de pensamento nas ciências humanas que se inspirou no modelo da linguística e que depreende a realidade social a partir de um conjunto considerado elementar (ou formal) de relações. Os resultados demonstraram que o cenário de barganha com poucas trocas são indesejáveis para persuadir os participantes a aceitar ofertas de pós-acordo, no entanto, sugere que tais ofertas devem ser acompanhadas de argumentos adicionais que viabilizarão a barganha e permitirão o atingimento Pareto-ótimo da negociação virtual.

Palavras-chave: E-commerce, Negociação Virtual, Teoria dos Jogos, Economia Comportamental.

\section{INTRODUÇÃO}

A origem da teoria dos jogos é relacionada ao matemático John von Neumann (19031975), juntamente com o economista alemão Oskar Morgenstern (1902-1977). Sua primeira publicação sobre jogos data de 1944 de "The Theory of Games and Economic Behavior", e nela demonstra que a solução para jogos de soma zero (par ou ímpar é um exemplo, onde quando um jogador ganha o outro necessariamente perde) pode ser determinando utilizando-se técnicas matemáticas.

Essas ferramentas foram desenvolvidas e elaboradas, a partir de 1950, por Reinhard Selten, John Forbes Nash e John Harsanyi, que receberam o Nobel de economia em 1994, por sua análise básica de equilíbrio na teoria dos jogos não-cooperativos.

A contribuição de Nash não se restringiu apenas aos jogos de soma zero, mas a uma noção de equilíbrio para modelos de jogos, ela ficou conhecida como "Equilíbrio de Nash", que representa uma situação em que, em um jogo envolvendo dois ou mais jogadores, nenhum jogador tem a ganhar mudando sua estratégia unilateralmente.

Disponível em: https://www.nucleodoconhecimento.com.br/engenharia-de-producao/negociacoesvia-internet 
A priori devemos classificar o que seria um jogo: "situações que envolvam interações entre agentes racionais que se comportam estrategicamente podem ser analisadas formalmente como um jogo". (FIANI, 2004, p. 12)

Nesses casos todas as relações que foram estudadas nos casos monitorados através do projeto INTERNEG (1996) e pelos dados coletados pela empresa E-bit referentes a interações realizadas via internet, o que configuramos como resultado de jogos onde agentes racionais interagem, buscando estrategicamente maximizar suas respectivas funções utilidade.

Consideramos neste trabalho os fatores que levaram os agentes a interagirem racionalmente, e demais fatores que foram detectados pelo projeto INTERNEG e que poderiam ser considerados comportamentos irracionais, sendo que os segundos não podem ser analisados pela Teoria dos Jogos por não cumprirem os requisitos iniciais sobre a melhor maneira de se atingir os objetivos (agindo "sem pensar", não são levantadas as informações necessárias para conclusões racionais das transações).

Mesmo levando-se em conta que os jogadores agem racionalmente, o cálculo racional pode induzir ao erro, Binmore (1987), considerado um dos mais importantes teóricos de jogos, levantou algumas condições para racionalidade do comportamento dos agentes:

1. O jogo (representando a interação dos agentes estrategicamente) é relativamente simples.

2. Os jogadores jogaram o jogo muitas vezes antes, e assim tiveram a possibilidade de aprender por meio de tentativa e erro (onde entra a questão do conhecimento profissional adquirido).

3. Os incentivos para jogar racionalmente, são adequados. (BINMORE, 1987)

\subsection{OBJETIVOS}

Analisar os aspectos intrínsecos das negociações via internet, que foram precursores do fenômeno e-commerce e do desenvolvimento do negociador.

Disponível em: https://www.nucleodoconhecimento.com.br/engenharia-de-producao/negociacoesvia-internet 
Apresentar os aspectos comportamentais que influenciam o consumidor, as relações de confiança que são construídas, os esforços de interação que sustentam esta estrutura.

A partir de aspectos identificados no experimento, identificar características do "homo economicus", tomador de decisões racionais, ponderadas, centradas em seu interesse pessoal e na capacidade ilimitada de processar informações através da WEB.

Entender e modelar as decisões dos agentes de forma mais realista, como sugere a Economia Comportamental, identificando como os consumidores tomam decisões individuais a partir de influências psicológicas, emocionais, conscientes e inconscientes, que afetam suas escolhas em um processo de negociação via internet.

\section{DESENVOLVIMENTO}

\subsection{COMO OS FUNDAMENTOS DE UM JOGO ESTÃO VOLTADOS PARA NEGOCIAÇÃO?}

Um jogo envolve a interdependência das ações de seus jogadores, o que os leva a considerarem nas suas decisões as reações dos outros jogadores, aos quais chamaremos de "oponentes", desse modo os jogadores tomam decisões estratégicas, no sentido de que suas decisões não contemplem unicamente seus objetivos, mas também suas possibilidades de escolha, e as dos demais jogadores (ou oponentes).

Obviamente, também existem jogos que não contemplam decisões estratégicas, por utilizarem apenas habilidade ou mesmo pura sorte dos jogadores envolvidos, estes não serão objeto de estudo desse trabalho, por não envolverem decisões estratégicas que avaliem a interação entre os jogadores em uma transação.

As interações estratégicas sob a luz da teoria dos jogos nos permitem compreender os fatores determinantes das decisões dos agentes e, a lógica por trás de cada decisão comparada com casos semelhantes. No entanto, a teoria dos jogos não deve 
ser utilizada como instrumento de previsão do comportamento dos agentes indiscriminadamente, ou como regra para situações específicas, pois muitos fatores podem interferir na realidade concreta dada a assimetria de informação, em comparação com aquilo que é previsto pela teoria dos jogos, analisada coeteris paribus.

\subsection{NEGOCIAÇÃO ATRAVÉS DA WWW: UM ESTUDO ENTRE CULTURAS DAS POTENCIALIDADES DA DECISÃO - REVISÃO DE ARTIGO}

\subsubsection{NEGOCIAÇÃO, TECNOLOGIA E CULTURA}

As negociações envolvem comunicação, ainda que os estudos concentrem-se mais na percepção dos processos das negociações e resultados em questionários e planilhas ignorando as regras vitais da comunicação. A ferramenta INSPIRE permitiu a comunicação por texto livre, de forma que as negociações fossem coletadas e analisadas. Uma conclusão após a análise foi que a cultura influencia as negociações através de seu efeito sobre as comunicações.

As diferenças culturais podem não emergir em interações face-a-face com negociadores de diferentes culturas, e é nesse momento que as negociações via INSPIRE podem permitiram que fossem observadas as diferenças culturais, e em quais circunstâncias elas surgem em uma negociação anônima.

Visando dar início aos estudos do processo de interação, os usuários foram convidados a se cadastrarem escolhendo entre uma das empresas descritas: por um lado havia a empresa fictícia Itex Manufacturing, que produzia partes de bicicletas, de outro lado havia a também fictícia empresa Cypress Cycles, que constrói bicicletas (CRAY, 1997, Apud Kersten e Noronha, 1997, p. 5).

Nessa situação elas enfrentariam o seguinte problema: Cypress Cycles necessita de um componente para sua nova linha de bicicletas e nenhum fornecedor conhecido 
poderia suprir essa necessidade. A Itex Manufacturing estaria buscando incrementar sua participação no mercado de componentes e identificou uma oportunidade de prestígio em atender Cypress Cycles com a conclusão de um contrato lucrativo. Nesse contrato existem 4 (quatro) assuntos a serem discutidos: preço dos componentes, tempos de entrega, acordo de pagamento e termo de devolução das partes defeituosas.

O processo de negociação sugerido pela literatura divide-se em fase antecedente (análise da negociação), fase corrente (condução da negociação) e fase consequente, que compreende uma análise pós-acordo, terminando com um preenchimento de um questionário não obrigatório.

A negociação não é sequencial, mas paralela, sendo que ela termina quando um compromisso é alcançado ou uma das partes termina o processo e informa seu oponente.

Um acordo é considerado "Pareto-ótimo" ou eficiente se ele não puder ser aperfeiçoado. Após a análise do INSPIRE e da determinação do Pareto-ótimo (o acordo alcançado) a negociação termina. Ao usuário é fornecida a chance de escolher uma das propostas ou a possibilidade de construir uma nova, ou ainda terminar a negociação e permanecer com um acordo ineficiente que tenha sido alcançado.

A ferramenta INSPIRE tem como meta primária observar e "logar" (criar registros de todas as ações) as atividades dos usuários o mais completamente possível. Outro fator relevante é que as negociações suportadas são assíncronas, considerando-se que as partes envolvidas vivem em fusos horários diferentes e raramente ambos estão "logados" simultaneamente.

Desta forma, a ferramenta INSPIRE proveria 2 (duas) fontes de dados, as quais descrevem a negociação completa, melhor que os negociados a descreveriam:

$1^{\circ}-2$ (dois) questionários que são preenchidos on-line por cada negociador; 
$2^{\circ}$ - uma gravação completa da negociação.

Ambos os questionários tentam capturar informações sobre os negociadores que de outra forma estariam indisponíveis. Eles também elucidam diretamente informações de percepção e julgamento sobre cada um e sobre o ambiente de negociação.

\subsubsection{ESTRUTURANDO OS DADOS}

Foram feitas 70 (setenta) mensurações em cada negociação, para verificar se estavam sendo corretamente analisadas através da ferramenta já descrita. Cada uma dessas variáveis (fatores) constitui uma coluna na tabela de saída do SPSS (IBM Statistical Package for the Social Sciences). Cada negociação acrescenta 2 (duas) linhas à tabela, uma para cada negociador (KERSTEN e NORONHA, 1997, p. 13).

O número de variáveis é intermediário no sentido de que elas são casualmente influenciadas por algumas variáveis independentes. Por exemplo, o número de ofertas feitas por um negociador é influenciado pelas normas de barganha de sua cultura, e influencia a probabilidade de alcançar um acordo com um correlativo de outra cultura.

Variáveis independentes não são afetadas por muitas das outras variáveis no estudo. Elas caem com 3 (três) subcategorias: assunto, tarefa e variáveis de sistema.

- Variáveis de assunto são as que descrevem os negociadores e algumas das mais importantes variáveis para o nosso estudo

- Variáveis de tarefa são relacionadas aos problemas comprometidos com os assuntos, essas centram ao redor do caso de negócio.

- Variáveis de sistema representam a presença ou ausência de características específicas de suporte no INSPIRE.

Variáveis dependentes são aquelas que têm a medida direta da eficácia final da potencialidade da decisão. Elas podem ser divididas em 3 (três) categorias: medidas da excelência da potencialidade do resultado da negociação, o processo de negociação e a eficácia do sistema. 
Variáveis subjetivas do processo incluem posterior julgamento de satisfações com o processo.

Variáveis intermediárias fazem parte de um complexo selecionado de medidas que ligam as variáveis intermediárias. É a bagagem psicológica inicial ou domínios absolutos que os negociadores trazem para a mesa de negociação.

Uma segunda classe das variáveis intermediárias está relacionada ao comportamento dos negociadores durante a negociação. Uma terceira classe envolve ainda as percepções do negociador antes da negociação começar.

\subsubsection{ANÁLISE CULTURAL DOS PARTICIPANTES}

Os participantes da pesquisa, denominados negociadores, utilizando a ferramenta "INSPIRE" são: participantes de cursos universitários e seminários; web surfers, estes principalmente abandonaram as negociações o que as fez inutilizáveis.

A cultura do participante foi definida em 4 (quatro) procedimentos:

1. país residente e idioma, se coincidir de outra forma;

2. país de nascimento e idioma se coincidir, de outra forma;

3. o país da primeira língua aprendida, se não inglês, português, espanhol, de outra maneira pelo país de residência;

4. país de nascimento. (KERSTEN e NORONHA, 1997, p. 16)

Os dados a respeito dos usuários do sistema "INSPIRE" são coletados através de um questionário na "pré-negociação". Na avaliação da descrição dos negociadores foi observado que os jovens, em média, se consideram menos experientes do que seus pares mais velhos, mesmo que a correlação entre idade e experiência dos negociadores seja fraca, não corroborando sua percepção. 
O acesso e o uso da web são altos, exceto entre os negociadores indianos, os quais experimentam dificuldades com o acesso e a velocidade, mas unanimemente um significativo aumento do acesso à web.

\subsubsection{ACORDOS ALCANÇADOS}

No total participaram 390 negociadores para 195 negociações bilaterais. Na avaliação de compradores e vendedores de cada uma das companhias do exemplo (compradores - Cypress, vendedores - Itex), não há uma distribuição igual sendo que cada cultura apresenta mais de um do que dos outros. Há mais vendedores entre os finlandeses do que compradores, e o contrário ocorreu entre indianos e chineses. No momento da análise dos dados no SPSS não foi possível distinguir negociadores que terminaram uma negociação decididamente encerrada de um usuário que não recebeu retorno das mensagens que passaram do prazo final.

A pesquisa buscou determinar as negociações que terminam com um compromisso a partir do qual seria dada continuidade depois que o compromisso fosse alcançado e encaminhado para fase de "pós liquidação".

Analisando a proporção dos acordos e das negociações verificou-se que é relativamente pequeno o número de negociadores que alcançou um acordo eficiente e que utilizou a característica de pós-acordo visando melhorar os acordos por eles alcançados.

\subsubsection{OFERTANTES E MENSAGENS}

As negociações no "INSPIRE" foram conduzidas através da troca de ofertas e mensagens as quais ocorreram de duas formas: poderiam ser submetidas juntas ou separadas. Sendo que a negociação termina com um acordo em que ambas as partes aceitam a oferta.

Os negociadores indianos são diferentes dos demais, pois enviaram poucas ofertas e mensagens, o que pode ser devido a sua idade e a experiência de negociação, mas 
negociadores dos EUA possuíam, na média, idade e experiências iguais, não confirmando essa hipótese.

Outro caso interessante observado pelo autor é o relativamente pequeno número de mensagens enviadas sem acompanhamento de ofertas, e o grande número de ofertas enviado sem mensagens.

\subsubsection{EXPECTATIVAS E REALIZAÇÕES}

O acordo é apenas um resultado da negociação, outros resultados incluem satisfação com o processo, com o compromisso e consigo mesmo.

O sistema tem um método de escore que considera que cada negociador define suas preferências numa escala de 0-100. Se os interesses e preferências são opostos, sendo dessa forma reversos, então no acordo a soma dos escores é 100. De qualquer modo se os interesses e preferências estão coincidindo o escore pode exceder 100 (cem). Se no extremo da situação, os interesses e preferências forem iguais eles serão 200 (duzentos).

Na segunda hipótese os usuários não provêm os escores esperados e alcançados, após entrarem no sistema eles são solicitados a especificar uma oferta a qual eles acreditam ser o meio termo. O sistema calcula o escore para essa oferta. É de se observar que o esperado, o alcançado e o escore não são fornecidos pelos usuários, mas sim calculados baseados em suas utilidades individuais e ofertas.

Avaliando os dados da tabela abaixo, conclui-se que Indianos têm habilidade para alcançar objetivos selecionados e que americanos são competitivos apesar de alcançarem menos do que esperam, enquanto tem escores acima do que esperavam alcançar.

Tabela 1 - Satisfação dos negociadores por origem

\begin{tabular}{|l|l|l|l|l|l|l|}
\hline & Total & Canada & China & Finlândia Índia USA \\
\hline
\end{tabular}




\begin{tabular}{|c|c|c|c|c|c|c|}
\hline Casos válidos ${ }^{a}$ & $177-224$ & $51-75$ & $46-77$ & $8-22$ & $13-33$ & $11-19$ \\
\hline Satisfação com & $2.7-3.1$ & $2.7-3.4$ & $2.5-3.3$ & $1.5-3.5$ & $1.7-3.1$ & $1.6-4.4$ \\
\hline 0 acordo $^{b}$ & $2.9(1.4)$ & $3.1(1.3)$ & $2.8(1.3)$ & $2.5(1.2)$ & $2.4(1.3)$ & $3.0(2.0)$ \\
\hline Satisfação com & $2.7-3.1$ & $2.5-3.3$ & $2.6-3.3$ & $1.9-3.6$ & $2.3-3.8$ & $2.1-4.3$ \\
\hline a performance $^{b}$ & $3.0(1.3)$ & $2.9(1.4)$ & $3.0(1.3)$ & $2.8(1.1)$ & $3.1(1.4)$ & $3.2(1.6)$ \\
\hline Expectativas & $3.2-3.7$ & $3.3-4.2$ & $3.3-4.3$ & $2.2-4.5$ & $1.9-3.7$ & $2.2-4.9$ \\
\hline encontradas $^{c}$ & $3.5(1.6)$ & $3.7(1.7)$ & $3.8(1.4)$ & $3.4(1.4)$ & $2.8(1.6)$ & $3.5(2.0)$ \\
\hline Escore alcançado $^{d}$ & $65(17)$ & $63(16)$ & $66(14)$ & $65(20)$ & $91(10)$ & $59(17)$ \\
\hline Escore esperado $^{d}$ & $72(20)$ & $66(23)$ & $69(20)$ & $69(21)$ & $82(22)$ & $71(15)$ \\
\hline
\end{tabular}

a o número de casos válidos muitas vezes depende das variáveis na tabela.

b 1-extremamente satisfeito, 7-extremamente insatisfeito

c 1-sim, completamente, 5-não, de forma alguma

d entre 0 e 100.

Fonte: Inspire Project (1996)

\subsubsection{OPONENTES}

Todas as comunicações entre os negociadores ocorreram via INSPIRE não revelando identidades, incluindo endereços de e-mail, os usuários utilizaram "apelidos" escolhidos antes do início da negociação. Apesar dos usuários poderem revelar seus nomes através da negociação ou outros dados, foi questionado se isso ocorreu durante as negociações e apenas $17.6 \%$ disseram que sim.

No experimento foi perguntado se eles adivinhariam o país do oponente e $52 \%$ respondeu Canadá, $14,5 \%$ USA e $8,5 \%$ o mundo. Também foi solicitado que os usuários avaliassem a atitude do seu oponente, e suas características e se havia interesse em ver os seus oponentes. 
Chegou-se à conclusão que os de que a percepção não varia significativamente entre os países, não foi considerado nenhum dos extremos de cada uma das 5 (cinco) características questionadas (elas variam de 1 a 5 ).

A respeito da compreensão das prioridades dos oponentes, os negociadores americanos demonstraram ter dificuldades em compreender seus oponentes mais do que os outros.

Americanos e canadenses são os mais interessados em ver seus oponentes e/ou trabalhar com eles no futuro. Talvez a razão disso seja que eles são mais satisfeitos com seus acordos e, com exceção dos chineses com seu próprio desempenho.

\subsubsection{CONCLUSÕES DOS AUTORES}

Os resultados levantados nesse estudo são orientados mais à exploração de dados e a formulação de hipóteses e direção de pesquisa, do que à verificação/confirmação de hipóteses existentes.

Podem ser verificadas diferenças entre culturas, o que está relacionado ao fato de que os negociadores não conhecem a identidade de seu oponente, algumas das diferenças podem ser explicadas pela profissão, experiência e idade dos negociadores.

O maior impacto da cultura é causado pela comunicação incluindo expectativas dos negociadores, níveis de reserva, concessões feitas durante a negociação e satisfação com os acordos e suas próprias performances.

Consideramos que as observações nesse trabalho foram preliminares e baseadas em pequenos exemplos não bem controlados. Nos experimentos futuros será necessário coletar dados e comparar as culturas dos 2 (dois) negociadores. Para realizar isso, será necessária uma quantidade mais ampla de exemplos do que se tem até agora. 
Um importante achado desse trabalho é a geral e alta aceitação da ferramenta INSPIRE e suas características.

O sistema foi criado para treinamento e propósitos de pesquisa. A alta aceitação do sistema levou os a trabalhar em outro sistema (INSS), o qual realmente teria maior capacidade que o outro.

Os analistas de negociação devotaram muitos esforços na especificação de acordos eficientes.

Eles sugerem que os negociadores escolhem compromissos eficientes, tão logo seja dada uma oportunidade. Comportamentalistas, por outro lado, sugerem que a eficiência de um acordo é menor quando comparado com as variáveis de um processo.

Os resultados desse estudo também indicam que os negociadores estão sempre relutantes em aperfeiçoar um acordo alcançado a despeito de eles serem várias vezes superiores ao negociado previamente. As razões para aceitar compromissos ineficientes deverão ser estudadas futuramente.

Uma significativa quantidade de trabalho deve ser feita com os números existentes e dados categóricos. É requerido muito mais trabalho na análise das mensagens. É conhecido através da interação com os usuários e pelas mensagens recebidas, que muitos deles consideram a negociação extremamente importante.

Há casos em que os usuários se sentem enganados pelos oponentes, tornando-se furiosos e emotivos. Isso mostra que o sistema tem valor como ferramenta efetiva de negociação e negociações virtuais não devem afastar toda frustração e ansiedade que é associada com as negociações cara-a-cara.

Este aspecto é relacionado diretamente à economia comportamental, na medida em que atinge os limites da racionalidade dos agentes econômicos, sobrepujando aspectos puramente econômicos na tomada de decisão. 
Rubin e Sander (1992) Apud Kersten e Noronha (1997, p. 25), sugerem que enquanto diferenças culturais as existirem frequentemente ocorrem ou sucedem mais das diferenças reportadas afetando resultados, expectativas e percepções.

O projeto INTERNEG (1996) permitiu que a comunicação imparcial entre negociadores que não conhecem a identidade ou mesmo o país de origem de seus oponentes fosse monitorada.

Em uma das negociações, "John" (pseudônimo), nascido no Canadá, envia uma mensagem de conclusão, para seu parceiro dizendo "Greg (pseudônimo), foi um prazer negociar com você, vejo você amanhã", John assumiu que seu parceiro é seu vizinho de escritório e um colega. Ao invés disso, seu parceiro foi um estudante chinês que estava iniciando sua graduação em educação em Kingston, Ontario e somente havia chegado muito recentemente ao Canadá.

\subsection{ACORDOS INEFICIENTES RAZOÁVEIS EM NEGOCIAÇÕES}

\subsubsection{EVIDÊNCIAS PARA ACORDOS INEFICIENTES}

A aceitação de acordos ineficientes e a relutância para melhorá-los são fenômenos que têm sido observados em muitas experiências. Diferentes interpretações são plausíveis e têm sido formuladas em ambos os terrenos teóricos, assim como comportamental e experimental. $O$ último inclui observações extremamente publicadas sobre preconceitos cognitivos e limitações, mas também diferenças na aproximação das pessoas para compreensão de decisões e processos de negociação, o qual constitui um resultado desses processos.

Desde 1996 foram conduzidas e acompanhadas analises e negociações bilaterais entre pessoas de muitas culturas e com diferentes níveis educacionais e conhecimentos profissionais. Os negociadores utilizaram INSPIRE, que é uma ferramenta web que permite negociações anônimas com o uso de análise conjunta para construção de utilidade, uma facilidade de comunicação para argumentação, e 
uma vantagem da visualização para a construção de um gráfico para representar a dinâmica da negociação e a história.

Entre dezembro de 1996, e março de 1998, mais de 1.000 (mil) pessoas negociaram via INSPIRE; algo em torno de 59\% alcançou um acordo e fora deles apenas $46 \%$ alcançaram um acordo eficiente (Pareto-ótimo). INSPIRE sugere melhoras Pareto para os usuários que atingiram um acordo não eficiente exibindo 5 (cinco) acordos eficientes e convidando os usuários a continuarem as negociações. Fora aqueles que alcançaram um acordo ineficiente e não desejam melhorá-lo.

Existem diversas razões sugeridas para que negociadores não prefiram melhoras de Pareto. Essas incluem os casos de imparcialidade que foram discutidos em experimentos econômicos e possivelmente são avessos ou desconfiam de um resultado gerado pelo computador. Este, em efeito, pode prover alguma explicação para rejeição de acordos ineficientes.

"Tecnicamente falando, esses aspectos considerados podem ser interpretados como mentiras ocultas pelos parceiros. Portanto, no espaço aumentado de casos, seu acordo original pode, depois de tudo, ter sido Pareto ótimo". Korhonen (1998, Apud CRAY e KERSTEN, 1999) sugere que a rejeição de uma melhora de Pareto pode ser incluída com a introdução de um expert ou de um terceiro que designa um incentivo apropriado para guiar a discussão em novas direções.

Isso ocorre porque um expert ou um terceiro muda ambos os contextos na dinâmica do processo e dessa maneira faz com que os resultados incomparáveis com uma situação quando nenhum deles está presente. É esse contexto dependente de atributos que é crítico, mas negligência questões na potencialidade da decisão.

\subsubsection{ATRIBUTOS CONTEXTO DEPENDENTES}

A ampliação do espaço da questão é um fenômeno que muitas vezes ocorre nas negociações quando alguns atributos (questões) são dependentes de contexto. Esses são os atributos que descrevem as potencialidades da decisão. Eles podem ser um 
critério visto ou uma obrigação suave que é relacionada ao problema, processo ou ao "mundo do lado de fora do problema".

Exemplos desses atributos são imparcialidade, pressão temporária, status social e empatia.

French (1986, p.344), declara que: a construção do modelo de decisão produzida como uma reflexão de me capacitar para explorar e (clarificar) esclarecer minhas preferências e opinião. De fato, em muitos casos ele guia sua evolução no que me anima a pensar sobre aspectos do problema, os quais até aqui eu não tinha considerado e, portanto, sobre os quais eu não tinha sentimentos pré-existentes (...) como eu articulo minhas preferências iniciais e opiniões durante a construção do modelo de potencialidades de decisão, minha atenção está atraída para alguma inconsistência entre essas e os canhões da racionalidade.

A diferença entre a formação de uma decisão única é que ao final a articulação da preferência é revisitada e atributos que em um ponto não foram relevantes podem por último tornarem-se críticos.

A consideração de atributo contexto dependente antes do início das negociações pode fazer pouco sentido para a decisão em via de formação. Isso é explicado porque esses atributos podem tornar-se presentes apenas em certas situações que são difíceis de prever e elas precisam ser relacionadas ao problema da negociação, mas para o pessoal e/ou características profissionais do negociador.

Por exemplo, uma pessoa pode ser "desconfiada" de computadores em geral, mas o fato dela concordar em negociar usando-os implica sua aceitação. Apenas quando, e depois de uma negociação difícil, o sistema propõe outra solução a suspeita pode voltar à tona.

A decisão de produzir em geral e na negociação em particular é uma atividade de resolução de um problema (isto é a escolha de uma decisão), é um processo envolvendo recursos e esforços. Atributos dependentes de contexto podem depender no processo de seus atributos e não unicamente no atributo dos problemas (alternativas). 
Por exemplo, atributos imparciais podem depender das aberturas iniciais (ofertas) feitas por ambos os parceiros, a frequência das "contra-ofertas", e as concessões feitas por cada lado.

Dos exemplos acima, ele segue que o atributo dependente do contexto pode refletir traços psicológicos do fabricante de decisões, sua opinião, e sistema de valores. Não é frequente que as pessoas mudem seus traços e valores, e aqui não estamos interessados com semelhante caso significante como aprendizado e descoberta. Esses traços de qualquer modo estão presentes, mas não necessariamente notório. Conclui-se então que eles representam um papel quando a situação pede por isso, mas podem não ser visíveis em outras situações.

\subsubsection{RACIONALIDADE}

Korhonen et al (1998) especula que pessoas através da obtenção de experiência de trabalho ou obtendo alta educação são mais prováveis para aceitar uma melhora de Pareto aparentemente por terem razões subjacentes em seus esforços por racionalidade econômica.

O axioma deles é que a racionalidade econômica é um princípio no qual as pessoas devem aplicar em tomadas de decisão. O corolário é que rejeitando as melhoras de Pareto as pessoas violam o princípio da racionalidade ou vice-versa. Negociadores racionais têm que rejeitar um acordo que eles tenham alcançado e aceitar uma alternativa que renda um valor maior de utilidade pelo menos para um deles.

Se eles rejeitarem, semelhante oferta (sugerida por um computador, mediador ou terceiro) eles não poderão ser racionais. Nós argumentamos que isso não é necessariamente o caso e que no fato que 2 (dois) conceitos são relacionados livremente, e que eles são princípios válidos para a decisão de produzir outras que são racionalmente econômicas.

De acordo com Savage (1972), um fabricante/produtor de uma decisão racional é um que “(...) tem apenas uma decisão para tomar em sua vida inteira. Ele deve, 
nominalmente, decidir como viver, e se ele pode em princípio decidir uma vez e por tudo".

Cientistas de decisão seguidores e inclusivos de SAVAGE tem legitimamente julgado este enorme problema mundial irreal. Ao invés disso, eles focam nos episódios, locais e decisões parciais que assumem possam ser razoavelmente isoladas da agenda de atividades do produtor de decisões durante sua vida.

O mais compreensivo critério de racionalidade é expresso em termos de problemas do grande mundo, avaliando a racionalidade de cada problema de decisão individual, o que não é uma tarefa fácil. Em muitas situações ele não pode ser reduzido para consideração de atributos do problema decisório e as preferências do produtor de decisões tomadas em cenários sociais quando as pessoas interagem e o resultado dessas interações tem consequências por detrás desse episódio.

Negociações são um exemplo típico de semelhantes decisões. Elas não devem ser uma surpresa que raramente elas possam ser isoladas do passado do produtor de decisões e suas projeções sobre o futuro.

Em teoria, alguém em acordo com os princípios da racionalidade significa dizer que é coerente com os princípios que escolheu e aplicou na vida. Essa coerência é a essência da racionalidade (WELLMAN, 1995), como ela conecta as diferentes e parciais decisões entre uma decisão de vida.

Coerência significa que decisões locais são contraditórias uma com as outras. Desta maneira, empregando o princípio da racionalidade pode ser interpretado como usando algum critério global na potencialidade da decisão.

A rejeição da melhora de Pareto implica que a pessoa rejeite uma solução para qual algum valor de critério local é melhor do que a solução aceitada. Desde que ele seja o critério global que determina se uma pessoa é racional, a rejeição da melhora de Pareto tem um pequeno impacto no princípio da racionalidade como um todo. 
Isso pode ser argumentado como um produtor de decisões racionais deve formular todos os critérios, incluindo os globais, que são relevantes para o problema em transmitir prioridade escolhendo uma decisão alternativa. Isso pode bem ser possível em problemas limitados e bem definidos, mas isso é apenas possível em problemas cognitivamente difíceis que envolvem interações entre pessoas.

\subsubsection{CONCLUSÕES DO AUTOR}

O processo de negociação contém um número de elementos que poderiam prejudicar os participantes para ambos continuarem ou abreviarem a experiência. Numa barganha face a face existem numerosos fatores que podem vir no meio das discussões, blefes, ofertas e desacordos que são utilizados no processo.

Em uma barganha eletrônica algumas dessas características são reduzidas senão eliminadas em importância, especialmente aquelas partes da troca que são baseadas na personalidade. A maioria provavelmente elevaria a proeminência das ofertas e contra-ofertas que são trocadas e os argumentos proferidos para suportá-las. Os dados coletados pelo INSPIRE permitem nos examinar alguns desses fatores para ver se eles se distinguem entre aqueles que prosseguem para o pós-acordo e aqueles que não prosseguem.

Como no equilíbrio de Nash que representa uma situação em que um jogo envolvendo dois ou mais jogadores, nenhum dos jogadores tem a ganhar mudando sua estratégia unilateralmente, necessitando entrar em acordo para obter o melhor resultado possível para ambos.

Uma das características que pode afetar as decisões para mover-se para o pósacordo é o número de ofertas trocadas. Concebivelmente um grande número de ofertas pode indicar que o processo tenha movido de forma incremental para o acordo inicial, então os participantes poderiam mais provavelmente continuar. 
Pelo contrário, um grande número de ofertas pode sugerir que a barganha tenha tido dificuldades e então que os participantes não gostariam de prolongar a experiência mesmo que fossem melhorados os acordos.

Uma inspeção da distribuição mostrou que aqueles que utilizaram o mecanismo de pós-acordo tinham feito mais ofertas do que tema que aqueles que não o fizeram. Ele apareceria, então, que a familiaridade com ambos os sistemas ou um sinal de que o oponente fazendo mais ofertas inclina o participante a persistir no esforço para alcançar um melhor acordo.

Esse resultado pode também ser interpretado em uma maneira diferente. Se o grande número de ofertas indicou um caminho mais difícil para o acordo inicial, então prosseguindo para o pós-acordo pode simplesmente ser uma tentativa para melhorar um acordo que, até esse ponto, foi menos que satisfatório apesar de conseguido o acordo.

Nós podemos tentar derramar mais luz sobre esse resultado examinando dois outros fatores no processo.

Se mover-se para o pós-acordo é uma questão de cinética de manutenção em uma relação confortável, a qual esperaria que essa se refletisse na avaliação do oponente. No questionário administrado no fim dos temas de negociação foram questionados quão amigáveis seus oponentes haviam sido. A cordialidade, contudo, não se distinguiu de tudo entre quem se moveu para o pós-acordo e aqueles que não se moveram. A percepção do oponente como um indivíduo aparentemente não influenciou a escolha se prosseguiriam.

Enquanto as características do oponente não influenciam diretamente as escolhas dos participantes, pode ser que a comunicação entre os negociadores possa influenciar. Então novamente pela facilitação da troca de informações e então fazendo a continuação mais atrativa. 
O resultado mostrado na tabela abaixo provê uma resposta de alguma forma contraditória para esta questão.

Tabela 2 - Processo de negociação versus o uso do pós-acordo

\begin{tabular}{|l|l|l|}
\hline & $\begin{array}{l}\text { Número de casos } \\
\text { válidos }\end{array}$ & $\begin{array}{l}\text { Nível } \\
\text { importância }\end{array}$ \\
\hline Número de ofertas enviadas & 268 & .002 \\
\hline Cordialidade & 169 & .939 \\
\hline Número de mensagens enviadas & 268 & .351 \\
\hline $\begin{array}{l}\text { Média de comprimento das } \\
\text { msgs }\end{array}$ & 259 & .631 \\
\hline Número de ofertas com msgs & 268 & .001 \\
\hline $\begin{array}{l}\text { Tempo médio entre trocas } \\
\text { Tempo restante até final do } \\
\text { prazo }\end{array}$ & 268 & .323 \\
\hline
\end{tabular}

Fonte: Inspire Project (1996)

O simples número de mensagens enviadas por um indivíduo experiente não distingue entre quem prosseguiu e aqueles que não prosseguiram. $O$ tamanho médio das mensagens também não produz efeito para mostrar uma diferença significativa. Se um envia muitas ou poucas mensagens e se aquelas mensagens são longas ou curtas não faz diferença para a probabilidade de seguirem para o pós-acordo. O volume puro de comunicações não é um fator. De qualquer modo, quando nós examinamos o número de ofertas que foram acompanhadas pelas mensagens então a diferença é significante no nível 0,001.

Esses dois resultados indicam que as ofertas representam uma importante parte no movimento pós-acordo. Simplesmente comunicando com o oponente primeiro não parece ter um efeito sobre esse aspecto do processo de barganha. 
Muitas das mensagens trocadas sem ofertas contêm explicações, argumentos ou ofertas parciais (ofertas formais somente podem ser feitas incluindo valores para todos os 4 (quatro) temas). De qualquer modo, um número dessas mensagens também é social na natureza.

É interessante que essas mensagens pareçam não ter nenhum efeito sobre a probabilidade de prosseguimento para pós-acordo. Quando combinadas com a escassez de algum efeito para cordialidade percebida dessa mudança/perda algumas dúvidas sobre a importância do lado humano do processo para prosseguir para pósacordo embora possa ser a natureza da barganha eletrônica, ou falta de interações face a face atenua essas influências.

Dois outros fatores também foram examinados por sua possível influência na decisão de pós-acordo. Dada a importância de ofertas ela apareceu possível que a escolha do momento das interações possa também ser importantes em cercar participantes para pós-acordo. Se as trocas foram frequentes, então as partes podem estar mais dispostas para continuar o processo. A proporção de tempo entre mensagens não tem efeito significativo.

Finalmente examinamos a influência dos prazos finais. O sistema INSPIRE impôs prazos finais, ambos por razões pedagógicas e para prevenir um grande número de negociações mantendo-se abertas mesmo pensando que elas não tinham gravada recente atividade. Nós consideramos a possibilidade que a existência de prazos finais poderia inibir o uso de pós-acordo para ambos, por que havia tempo insuficiente ou por que foi percebido/observado como fechamento imponente no processo.

\subsubsection{PONTOS DE DISCUSSÃO FUTUROS}

No início do artigo perguntamos se "menos é melhor que mais". Essa questão reflete o uso dos valores de utilidade do INSPIRE para avaliar a eficiência dos acordos. Se a utilidade não representa nenhum papel para os negociadores do INSPIRE então isso poderia ser razão suficiente para rejeição do pós-acordo. De qualquer modo, este não é o caso, como $64,4 \%$ da população total de usuários e $63,8 \%$ dos usuários que 
alcançaram acordos ineficientes afirmam que a utilidade é extremamente ou muito útil (valores de 1 ou 2 sobre uma escala de 7 pontos).

Nós temos visto que $65,2 \%$ dos usuários que não entraram na fase do pós-acordo e $59,6 \%$ daqueles que não entraram na fase de pós-acordo consideraram a utilidade extremamente ou muito útil. Mais além, não existe diferença significante entre aqueles que entraram o pós-acordo e os que não o fizeram sobre suas considerações de importância da utilidade $(p=0,441)$.

Isso implica que o uso de utilidade ainda que considerado muito importante em negociações, não influencia a decisão dos negociadores na melhora dos acordos, respondendo a questão de que muitos deles aceitam menos antes de mais.

Embora nossos exames dos fatores que poderiam afetar o movimento pós-acordo seja limitado, ele sugere algumas das dinâmicas que podem ser a base de uma explicação mais profunda da relutância geral dos negociadores em prosseguir para a fase de pós-acordo. A escassez enfática de algum efeito de cordialidade na utilização do pós-acordo fez ele duvidoso, que as características do oponente possam ter muito impacto.

Esse resultado poderá precisar ser verificado pelo exame das negociações cara a cara e outros traços de "desejabilidade", mas isso sugere que a importância de fatores semelhantes possa ser subestimada. Pesquisas semelhantes podem também ajudar a derramar alguma luz sobre a questão de quanta influência uma pessoa anônima inerente à barganha eletrônica tem sobre o processo como um todo.

A importância das ofertas e as mensagens que as acompanham coloca mais ênfase nos elementos reais do processo como condutores do movimento para o pós-acordo. Parece ser algum momento, talvez um momento mútuo, que constrói tanto mais ofertas quantas são trocadas. Esse momento é ajudado pela inclusão de informações que suportam e detalhes da oferta. Juntamente com as descobertas sobre cordialidade esses resultados apontam para a estrutura do processo em termos de partes mais formais de interação, como pelos menos um fator importante na 
compreensão do por que negociadores nem fazem nem empregam mecanismos pósacordo.

O que isso implica para experimentadores que poderiam desejar persuadir seus temas para empregar técnicas de pós-acordo?

Primeiro de tudo, nossos resultados como muitos outros, indicam que simplesmente oferecendo pós-acordo como um não risco significa um meio de melhorar um acordo não é suficiente. Menos de $21 \%$ dos temas elegíveis aproveitam-se eles mesmos das oportunidades. Além disso, 39,4\% daqueles que entraram na fase de pós-acordo não selecionaram um acordo eficiente.

Para experimentos nossos, os resultados implicam que um simples cenário de barganha o qual possa envolver somente poucas trocas de ofertas são indesejáveis para persuadir participantes a aceitar ofertas de pós-acordo.

Nosso trabalho também sugere encorajar ou requerer que as ofertas sejam apoiadas por argumentos que devam facilitar barganhas adicionais depois do acordo inicial ser alcançado. Isso pode ainda ser proveitoso para exercícios mais realísticos através da extensão além de diversas sessões. O que poderá aumentar o número de ofertas e prover o momento que parece ajudar pelo menos alguns negociadores, a abraçar ambos os conceitos e práticas de barganha pós-acordo visando o Pareto-ótimo da negociação.

\section{CONSIDERAÇÕES FINAIS}

A prática de negociação via internet tem várias características que potencializam a condução dos negócios em geral. A web permite níveis sem precedente de conectividade bidirecional ou alcance, contrastando com a transmissão tradicional a qual é unidirecional e tradicionalmente meio de comunicação bidirecional é limitado a poucos participantes. 
Os sistemas de leilão da internet como "E-bay" e "Primeiro Leilão" (ambos 1997) podem gerar o melhor preço possível, e de uma forma similar grupos de discussão e tecnologias de colaboração formam a "cola" que lidera a formação de comunidades virtuais. Isso certamente pode afetar o balanço da força em uma situação de negociação.

Uma consequência do alcance que a Internet pode ter é o vasto crescimento no contato entre pequenos negócios através de limites geográficos nacionais e culturais.

Os empresários, em pequena escala, buscam contratos com clientes geograficamente distantes. Se observado literalmente é requerido a pessoas de negócios (pessoas ou instituições formalmente treinados como negociadores) para lidarem com parceiros cujo arcabouço cultural é desconhecido, não familiar.

Todos esses fatores levam a uma mudança qualitativa na natureza e na prática comum da negociação e de forma correspondente implica na necessidade de mudança do treinamento, o processo tende a ser muito mais culturalmente suscetível (sensibilidade) e de preferência tecnologicamente consciente, esse fator não é novo, e agora é requerido em larga escala em negócios de rotina e não apenas para diplomatas e para elite corporativa.

Uma característica notável na web é a escala massiva com respeito várias dimensões: rapidez, alta capacidade, barata e as transações ocorrem rapidamente e em volumes grandes.

A tecnologia não apenas criou a necessidade, mas também proveio os modos/meios para entregar soluções efetivas: a web é uma vasta fonte de recursos, um fórum para consultas a outros experts e especialistas, e um meio para acessar ferramentas de suporte à negociação. A web não é um arquivo passivo de informação, ela pode ser usada para transporte de objetos "vivos" com comportamento específico em certo contexto. 
Um engano comum expressado pelos praticantes novos para a web é que ela perde todas as importantes pistas que uma linguagem corporal provê em uma negociação cara-a-cara, corroborando o que o autor do artigo menciona.

É importante lembrar que a web não é uma "alternativa" para tradicional forma de interação semelhante a cara-a-cara ou a uma conversa telefônica, mas um acréscimo. $\mathrm{Na}$ realidade a falta da negociação cara-a-cara é uma vantagem, pois evita o estresse concomitante de uma negociação nesse nível (isso se reflete em uma venda difícil).

Trata-se também de um exercício precursor da relação com loT (Internet of Things), desbravando um universo de possibilidade de transações e interações com objetivo de suportar às negociações.

Um importante aspecto dos termos de negociação e que pode estabelecer um relacionamento entre o comprador e o vendedor que conduz para uma continuidade da transação é o fato de que no e-commerce introduz-se significativa complexidade dos termos da negociação, o fato da distância física entre os parceiros, o fato de que ambos não conhecem um ao outro, além da diferença entre as práticas de negócios e culturais - tudo isso contribui para o alto grau de complexidade.

For last, but not least o e-commerce aumentou o grau de complexidade entre as compras e vendas, mas ao mesmo tempo oferece não menos oportunidades entre compradores e vendedores pequenos e grandes. Os softwares podem tornar as transações mais eficientes e sobrepujar muitas das tradicionais dificuldades encontradas nos aspectos culturais e comportamentais identificados nos estudos realizados pelo projeto INTERNEG (1996).

\section{REFERÊNCIAS}

ÁVILA, Flávia. BIANCHI, Ana Maria. Economia Comportamental. Disponível em: http://www.economiacomportamental.org/o-que-e/. Acessado em: 08/10/2002. 
CRAY, David, KERSTEN, Gregory E. Negotiation Inefficient Compromises: Is Less Better than More ?. Working Papers IIASA, Interim Report IR-99-022, 1999. Disponível em: http://pure.iiasa.ac.at/id/eprint/5917/1/IR-99-022.pdf. Acessado em: : 08/10/2002.

D'ANDREA, Edgar; SERVIDEO, Federico A., GALOFRE, Raul. Privacidade e Segurança na Internet. Disponível: http:/www.pricewaterhouse.com.br/. PricewaterhouseCoopers. Acessado em: : 08/10/2002.

e-bit Tecnologia em Marketing. Evolução do Comércio Eletrônico Brasileiro 2000 2003. Webshopper 8 - agosto 2003. Disponível: http://www.webshoppers.com.br/. Acessado em: : 10/10/2002.

e-bit Tecnologia em Marketing. Julho, 2002. Artigo Webshopper 6 - julho 2002. Disponível: http://www.webshoppers.com.br/. Acessado em: 10/10/2002.

e-bit Tecnologia em Marketing. Outubro - Dezembro 2001. Artigo Webshopper 5 dezembro 2001. Disponível: http://www.webshoppers.com.br/. Acessado em: $10 / 10 / 2002$.

e-bit Tecnologia em Marketing. Raio X do comércio eletrônico brasileiro 2002. Webshopper 7 - fevereiro 2003. Disponível: http://www.webshoppers.com.br/. . Acessado em: 10/10/2002.

FIANI, Ronaldo. Teoria dos Jogos: para cursos de economia e administração. 1a. edição. Rio de Janeiro. Editora Elsevier Ltda. Ano 2004.

KERSTEN, Gregory E., MALLORY, Geoff R. Rational Inefficient Compromises in Negotiation. IIASA, Interim Report IR-98-024/May, 1998. Disponível em: https://core.ac.uk/download/pdf/33897094.pdf. Acessado em: 10/10/2002.

KERSTEN, Gregory E., MOHAN, T. R. Madan, NORONHA, S. J., KERSTEN, M. J. Learning Business Negotiations with Web-based Systems: The Case of IIMB. 
IIASA, Interim Report IR-98-049/October, 1998. Disponível em: http://pure.iiasa.ac.at/id/eprint/5600/. Acessado em: 10/10/2002.

KERSTEN, Gregory E., NORONHA, Sunil J. Negotiation and the Web: User's Perceptions and Acceptance. IIASA, Interim Report IR-98-002/March, 1998. Disponível em: http://pure.iiasa.ac.at/id/eprint/5644/. Acessado em: 10/10/2002.

KERSTEN, Gregory E., NORONHA, Sunil J. Negotiation Via the World Wide Web: A Cross-Cultural Study of Decision Making. IIASA, Interim Report IR-97-52/August, 1997. Disponível em: http://pure.iiasa.ac.at/id/eprint/5242/. Acessado em: 11/10/2002.

KERSTEN, Gregory E., SZPAKOWICZ, S. Modelling Business Negotiations for Electronic Commerce. IIASA, Interim Report IR-98-015/March, 1998. Disponível em: https://ideas.repec.org/p/wop/iasawp/ir98015.html. Acessado em: 11/10/2002.

NEXT GENERATION CENTER. Apostila CRM (Customer Relationship Management), 2002. capitulo 13, pág. 32-33.Disponível em: http://www.nextg.com.br/BR/. Acessado em: 12/10/2002.

NOBREGA, Clemente. Tudo está em jogo. Ciência em Management. Disponível em: http://www.clementenobrega.com.br/index.asp. Acessado em: 12/10/2002.

PIMENTEL, Ruderico F. A Internet e a Organização da Produção: Internet, Mercados e Hierarquias. Relatórios de Pesquisa em Engenharia de Produção. UFF/Escola de Engenharia, 2002. Workshop sobre Transações Eletrônicas.

PINDYCK, Robert S.; RUBINFELD, Daniel L. Microeconomia, 5a. edição, Editora Prentice Hall ( Pearson ), 2002.

RUBIN, J.Z.; SANDER, F.E.A. Culture, Negotiation and the Eye of the Beholder; 1991 Negotiation Journal 19: 249-254. Dispoível em: https://onlinelibrary.wiley.com/doi/abs/10.1111/j.1571-9979.1991.tb00620.x. Acessado em: 12/10/2002. 
WATKINS, Nathalia. Comércio Eletrônico Avança no Brasil. Jornal do Brasil.

Caderno Internet. Rio de Janeiro, pág 15-16. 27/10/2003.

Enviado: Setembro, 2020.

Aprovado: Janeiro, 2021. 